\title{
Blast impact behaviour of concrete with different fibre reinforcement
}

\author{
Martina Drdlová1, a René Čechmánek ${ }^{1}$, and Radek Řídký ${ }^{2}$ \\ ${ }^{1}$ Research institute for Building Materials, Hněvkovského 65, 61700 Brno, Czech Republic \\ ${ }^{2}$ SVS FEM, Škrochova 42, 61500 Brno, Czech Republic
}

\begin{abstract}
The paper summarizes the results of the development of special concrete intended for the explosion resistance applications, with the emphasis on minimal secondary fragments formation at the explosion. The fine-grained concrete matrix has been reinforced by various types of short dispersed fibers (metallic, mineral and polymer) of different sizes and by their combination and the effect of the fibre reinforcement on the physico-mechanical properties and blast resistance was observed. The concrete prism specimens have been subjected to the determination of mechanical parameters (compressive and flexural strength at quasi-static load). The blast tests were conducted on the slab specimens prepared from selected mixtures. The material characteristics and explosion test data have been used for numerical investigation, which defined the optimal wall composition and dimensions of the concrete element which should resist the explosion defined by type, size, weight and placement of the blast. In the next step the test elements resistance was verified by real explosion test.
\end{abstract}

\section{Introduction}

Efforts to eliminate possible threats of terrorist attacks in areas with high concentrations of people is mostly realized in a passive way. For example, trash bins and baggage lockers were removed from the potentially critical public spaces, isolation of large areas and long time forced downtimes are required while the suspect objects are investigated. Hence the alternative approach, which results in the reduction of citizen discomfort and in increase of safety at the same time, is on demand. For lower explosion load levels the reinforced high performance concrete is a good and mainly inexpensive solution compared to other systems recently applied.

The high performance concrete itself as a quasi-brittle material does not conform to the resistance requirements, as at the explosion many secondary fragments are formed while the concrete breaks. The additional reinforcement in form of random dispersed fibres can increase the blast resistance of the concrete. By the addition of steel fibres to the conventional concrete, the impact strength value has increased 2-15 times depending on the amount of the fibres [1]. Better performance of fibre reinforced concrete (FRC) under impact load compared to plain concrete without reinforcement was also confirmed by [2-4]. Maalej et al. [5] found that hybrid fibre-reinforced concrete (using combinations of two or more types of fibres in the same concrete mixture) offered increased shatter resistance with reduced scabbing, spalling and fragmentation, whilst exhibiting better energy absorption.

Fibre reinforcement in combination with high performance matrix is a way to improve blast resistance of concrete. Optimal composition with emphasis on the compatibility of the matrix and fibre is required, especially in the case of relatively thin wall elements. The aim of

\footnotetext{
${ }^{a}$ Corresponding author: drdlova@vustah.cz
}

the experiments presented in this paper is to develop a high-grade concrete with increased resistance to blast, which will be used for elements of urban infrastructure, for example litter bins with blast resistance up to $1000 \mathrm{~g}$ of TNT.

\section{Materials and test procedures}

Concrete mixtures with various fibre reinforcement were prepared. For the mechanical performance investigation, the prism $100 \times 100 \times 400 \mathrm{~mm}$ specimens were made and the bulk density according to ČSN ISO 6275 , compressive strength and flexural strength at 28 days of age in accordance with ČSN EN 12390-3, were measured. Four types of fibres have been incorporated into the matrix to determine their influence on physico-mechanical properties: Glass fibres $(\mathrm{G})$ - length $12 \mathrm{~mm}$, diameter $0,14 \mu \mathrm{m}$, basalt fibres (B) - length $6 \mathrm{~mm}$, diameter $12 \mu \mathrm{m}$, steel fibres (S) - length $6 \mathrm{~mm}$, diameter $200 \mu \mathrm{m}$, polypropylene (P) - length $12 \mathrm{~mm}$, diameter $18 \mu \mathrm{m}$. Mix proportions of fibres are listed in Table 1. Finegrain high performance concrete (consisting of fine $\mathrm{SiO}_{2}$ sand, cement 52.5R, microsilica, and superplasticizer) was selected as a standard. Total volume of fibres was 3 vol. $\%$. For the explosion tests the concrete boards $40 \times 500 \times$ $500 \mathrm{~mm}$ were produced from selected mixtures and test procedure according to certified methodology MT0-BVTUO 10/9 developed by Military research institute of CR [6] was applied.

The methodology consists of measuring vibrations and further acceleration of a test stand holding the sample, which is subjected to the explosion load. The concrete specimen is fixed in the steel frame of the stand and the stand is placed on a sand foundation. The cylinders of Semtex C4 plastic high explosive weighting $77.0 \mathrm{~g}$ and

This is an Open Access article distributed under the terms of the Creative Commons Attribution License 4.0, which permits unrestricted use, distribution, and reproduction in any medium, provided the original work is properly cited. 
Table 1. Mix proportion of fibres in the mixtures.

\begin{tabular}{|l|c|c|c|c|}
\hline \multirow{2}{*}{ Designation } & \multicolumn{4}{|c|}{ Fibre content $\left(\mathrm{kg} / \mathrm{m}^{3}\right)$} \\
\cline { 2 - 5 } & Glass & Steel & Basalt & Polypropylene \\
\hline REF & 0 & 0 & 0 & 0 \\
\hline G100 & 53.7 & 0 & 0 & 0 \\
\hline B50 & 0 & 0 & 26.9 & 0 \\
\hline S400 & 0 & 234.9 & 0 & 0 \\
\hline P4 & 0 & 0 & 0 & 2.3 \\
\hline G50B37 & 26.9 & 0 & 20.5 & 0 \\
\hline G50P10 & 27.7 & 0 & 0 & 5.5 \\
\hline G50B37P2 & 27.7 & 0 & 20.3 & 1.1 \\
\hline G40B20PP4 & 22.2 & 0 & 10.3 & 2.2 \\
\hline S200G50 & 28.7 & 114.8 & 0 & 0 \\
\hline S200B30 & 0 & 113.6 & 15.9 & 0 \\
\hline S130G22B17P1 & 12.6 & 75.7 & 9.5 & 0.6 \\
\hline
\end{tabular}

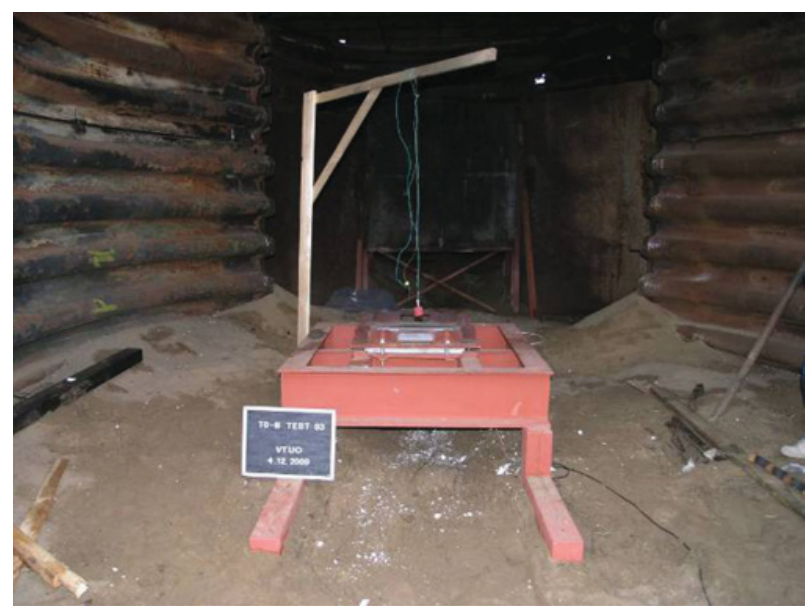

Figure 1. Test stand with a charge.

with dimensions $\mathrm{d}=45 \mathrm{~mm}, \mathrm{~h}=45 \mathrm{~mm}$ are used as testing charge. The test stand with the charge is shown in Fig. 1.

The acceleration detector is attached to the steel frame of the stand - the data from the acceleration sensors is collected for at least 500 milliseconds using sampling frequency of $200 \mathrm{kHz}$. The acoustic detector of explosion is used for triggering the data collection. The results of the measurements are data characterizing the material capability of absorbing the blast energy. The obtained data are processed and the absolute value of acceleration is gained which is then integrated. The integrated value enables to compare the energy absorbed by particular materials - the lower the integral value, the more blast energy was absorbed by the specimen. The energy absorption is one of the parameters - however the integrity of the sample must also be taken into consideration when evaluating the overall sample blast resistance performance. Hence the comparison of the samples is done using the following equation: $1 /$ (Relative attenuation*Integrity), where Integrity value reflects the integrity of the sample after subjected to the blast load - the integrity was marked using numbers from 1 (the sample is without visually noticeable changes after blast load) to 5 (the sample is broken to small pieces after blast load). The outputs of the equation given above are shown in Fig. 6 and were used to compare the overall performance of samples when

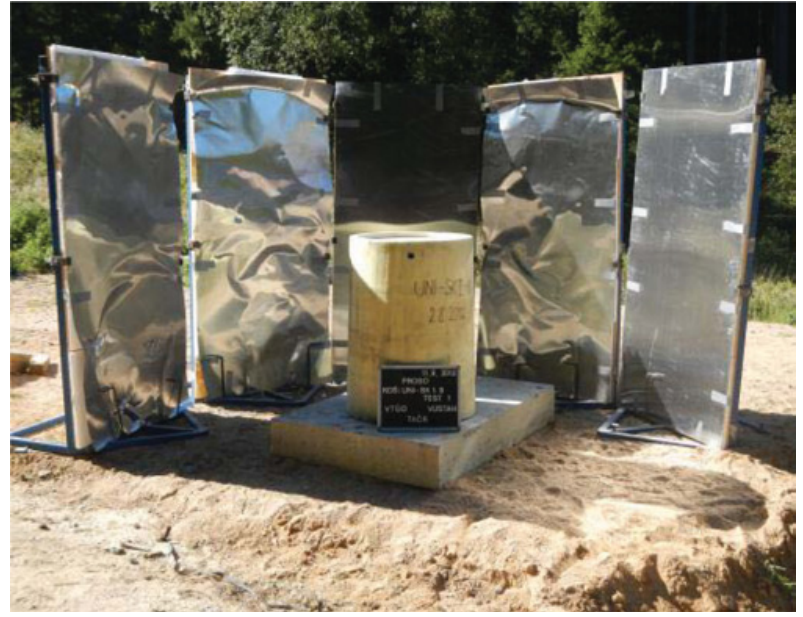

Figure 2. Blast test layout.

subjected to the blast load - the higher value, the better overall blast resistance of the sample (combination of the absorbed energy and preservation of the sample integrity) [7]. The obtained data provided interesting information about the materials response on blast load and was used for adjustment of the material model in subsequent numerical simulations. The aim of numerical investigation was to find optimal dimensions and wall composition of the litter bin, which will be able to resist $1000 \mathrm{~g}$ of TNT charge detonated inside the vessel. Numerical investigation was performed using implicit/explicit solver LS-Dyna.

Based on the findings obtained during the numerical investigation, real litter bin was manufactured and subjected to the blast load. Test procedure according to the methodology M-VTÚO 11/11 [8] was applied to evaluate the blast resistance of the litter bin. The test layout is depicted in Fig. 2. At the distance of $1,5 \mathrm{~m}$ from the axis of the tested object, the check panels are deployed and fixed to the compacted sand ground. Test panels consist of steel frame, which holds hardboard-polystyrenealuminium plate sandwich. The dimensions of the check panel are $1 \times 2 \mathrm{~m}$. Semtex C4 plastic high explosive weighting $770 \mathrm{~g}$ (equivalent of $1000 \mathrm{~g}$ of TNT) was used as a testing charge. The integrity of the tested object, its global displacement, creation of secondary fragments and condition of the check panels are observed and evaluated. To declare the test as satisfactory, the global displacement of the specimen must not exceed $1 \mathrm{~m}$, the overall integrity of the object must be preserved and the check panels must not be penetrated by secondary fragments.

\section{Test results and discussion}

\subsection{Physico-mechanical parameters}

Bulk density, flexural and compressive strengths at 28 days of age were determined. The average values of at least 5 specimens of the same mixture are presented in Table 2.

Both flexural and compressive strength are influenced by fibre incorporation. Almost all mixtures with fibres showed reduced compressive strength values in comparison with REF specimen without fibres. The opposite effect of fibre incorporation was observed in the case of flexural 
Table 2. Physico-mechanical parameters of the specimens.

\begin{tabular}{|l|c|c|c|}
\hline Designation & $\begin{array}{c}\text { Compressive } \\
\text { strength } \\
\text { (MPa) }\end{array}$ & $\begin{array}{c}\text { Flexural } \\
\text { strength } \\
(\mathrm{MPa})\end{array}$ & $\begin{array}{c}\text { Bulk } \\
\text { density } \\
(\mathrm{MPa})\end{array}$ \\
\hline REF & $\mathbf{1 1 0 . 3}$ & $\mathbf{6 . 3}$ & $\mathbf{2 , 2 4 4}$ \\
\hline G100 & $\mathbf{9 8 . 1}$ & $\mathbf{1 8 . 8}$ & $\mathbf{2 , 1 3 6}$ \\
\hline B50 & 88.4 & 6.4 & 2,144 \\
\hline S400 & 115.0 & 18.1 & 2,424 \\
\hline P4 & 99.8 & 8.7 & 2,171 \\
\hline G50B37 & 86.9 & 11.3 & 2,136 \\
\hline G50P10 & 93.8 & 15.4 & 2,150 \\
\hline G50B37P2 & 82.2 & 13.2 & 2,134 \\
\hline G40B20PP4 & 94.5 & 11.5 & 2,152 \\
\hline S200G50 & 92.2 & 22.1 & 2,300 \\
\hline S200B30 & 109.6 & 22.3 & 2,276 \\
\hline S130G22B17P1 & $\mathbf{1 1 7 . 9}$ & $\mathbf{2 3 . 3}$ & $\mathbf{2 , 2 5 5}$ \\
\hline
\end{tabular}
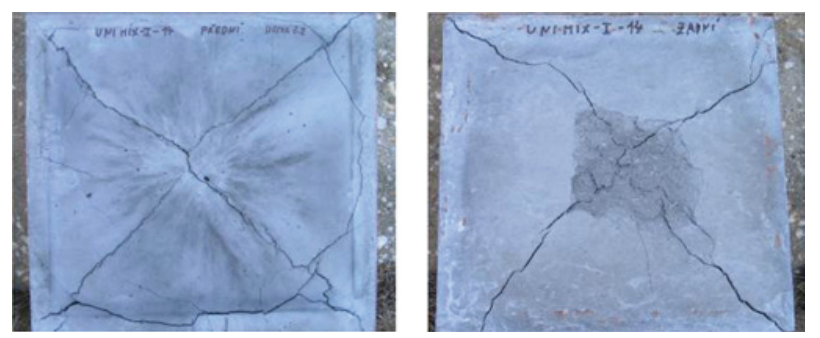

Figure 3. Specimen S130G22B17P after blast test. Front side (left), back side (right).
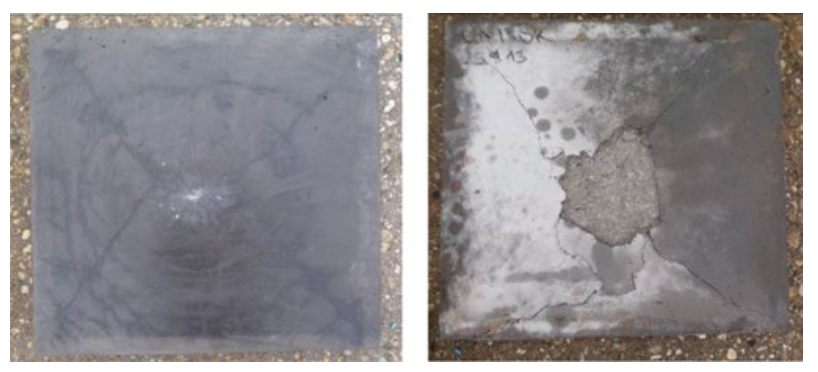

Figure 4. Specimen G100 after blast test. Front side (left), back side (right).

strength - any fibre brought enhancement of the flexural strength, with high scatter of values dependent on fibre type. The highest flexural strength values were achieved using fibre blends containing steel fibres.

\subsection{Blast tests conducted on slab specimens}

Blast test according to the methodology MT0-B-VTUO 10/9 described above was conducted with three selected mixtures signed bold in Table 2. The mixtures were selected due to their extraordinary mechanical properties, in particular flexural strength. Two slabs of each mixture were examined.

The average values of overall blast resistance of the materials evaluated and calculated according to the methodology MT0-B-VTUO 10/9 are graphically depicted in Fig. 6. The photographs of the slabs are shown in Figs. 3, 4 and 5.

The best blast resistance was achieved using glass fibres as a reinforcement (Specimen G100). The test

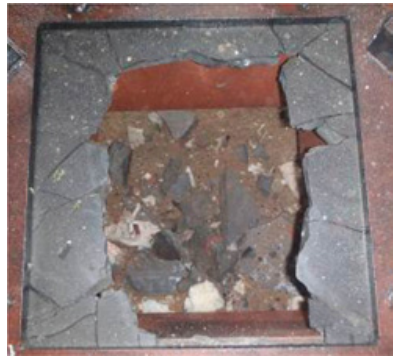

Figure 5. Specimen REF after blast test.

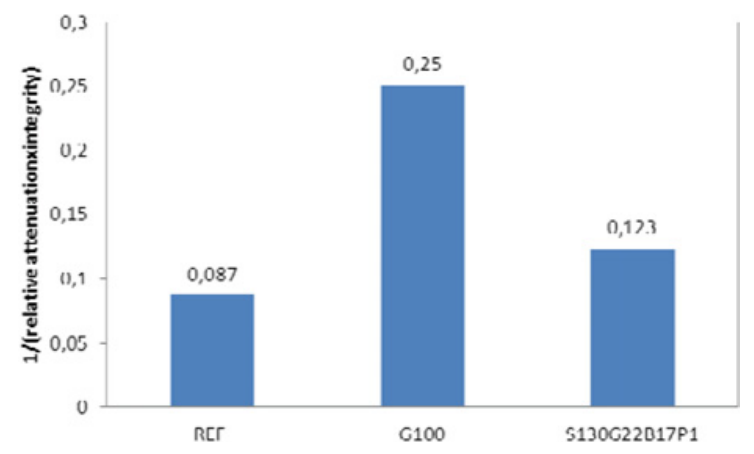

Figure 6. Explosion resistance rate of three selected specimens.

specimen remained integral after the blast test, on the front side only hair cracks appeared, from the bottom side one flat fragment was ejected (weight $85 \mathrm{~g}$ ). The specimen with hybrid reinforcement (glass, steel, polypropylene and basalt) showed lower blast resistance, probably due to demanding production procedure connected with difficulties in achieving the good homogeneity of the material. Large cross cracks were created on both sides of the test slab and one spall (weight $180 \mathrm{~g}$ ) was separated from the specimen, without overall disintegration of the slab. The blast test performed on the REF specimen without reinforcement results in total damage of the specimen (see Fig. 5).

\subsection{Numerical investigation and real element blast test}

In this step, the aim of the research work was to find dimensional parameters and structural composition of the litter bin, which will be able to resist the blast wave created by detonation of $770 \mathrm{~g} \mathrm{C} 4$ explosive (equivalent of $1000 \mathrm{~g}$ of TNT) without fragmentation. Material G100 fine-grained high performance concrete reinforced with glass fibres was selected for the numerical investigation and subsequent blast tests, as it exhibited excellent workability and mechanical properties, very good production technology and explosion resistance.

RHT model was selected for simulations of the concrete material. All data obtained from tests described above was used to adjust the material model. Bilinear plastic kinematic model was used for laminate layer. The design of the vessel geometry and dimensions was based on previous research for lower level $250 \mathrm{~g}$ of TNT, which indicates the minimum required wall thickness of $200 \mathrm{~mm}$. The litter bin was dimensioned in accordance with these requirements and due to high level of load, the layer of 


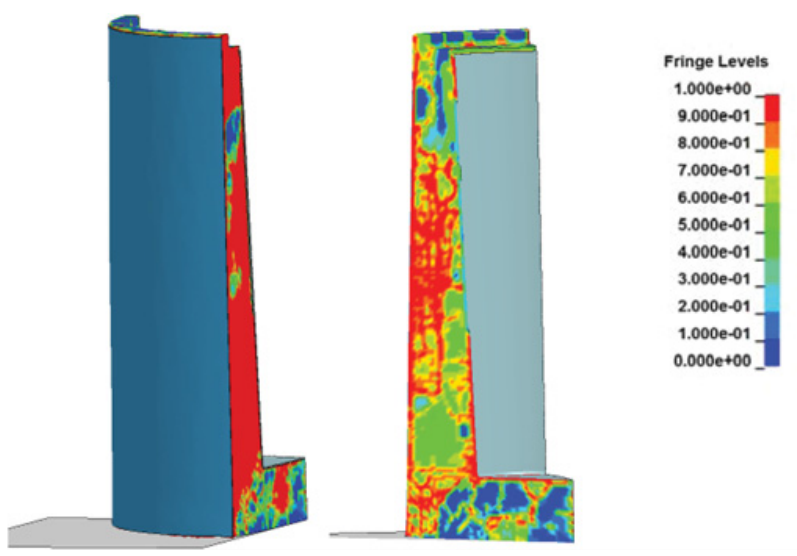

Figure 7. Litter bin after explosion detonated in the middle of the vessel (concrete with inner laminate layer $3.5 \mathrm{~mm}$ and outer laminate layer $1 \mathrm{~mm}$ ).

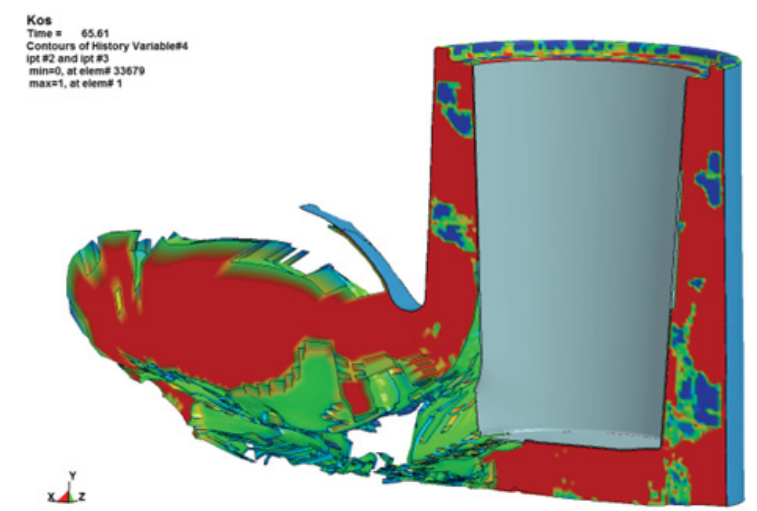

Figure 8. Litter bin with outer laminate layer $1 \mathrm{~mm}$ after explosion detonated at the bottom of the vessel.

laminate (both inside and outside) was added. Inner layer thickness was $3.5 \mathrm{~mm}$, outer layer $1 \mathrm{~mm}$. At the first step, the charge was placed in the middle of the vessel's free space. The results of numerical simulations showed, that even though the partial failure of concrete occurred, the laminate shell transmitted created tensile strength and the litter bin remained integral (see Fig. 7).

In the next step, the charge was placed at the bottom of the vessel and it was investigated if the wall would be able to transmit the strain created by detonation of such placed explosive.

As seen in Fig. 8, the litter bin resistance was insufficient, the outer layer failure accompanied with massive fragmentation occurred. The outer laminate layer thickness was increased to $5 \mathrm{~mm}$ and the same test was carried out (see Fig. 9). According to results of numerical simulations, the litter bin with given dimensions, geometry and composition should resist the blast load of $1000 \mathrm{~g}$ TNT charge. Subsequent real blast test of manufactured concrete litter bin (carried out according to the methodology M-VTUO 11/11 described above) confirmed the results of numerical simulations. The inner layer of the vessel was destroyed, while the outer layer showed neither damage nor cracks. No global

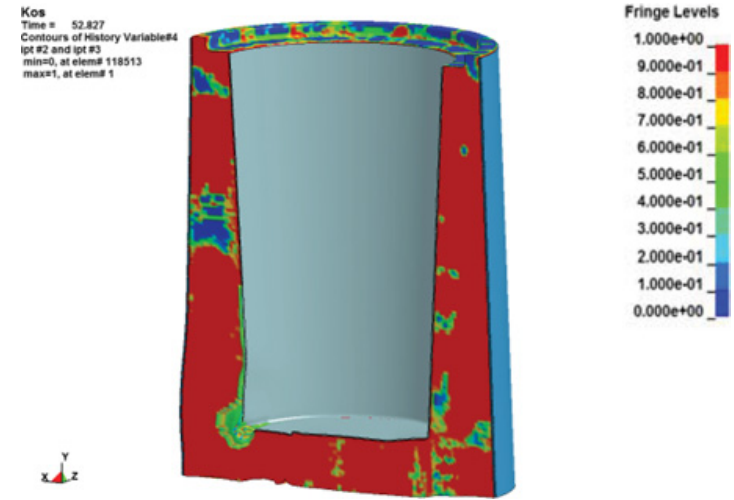

Figure 9. Litter bin with outer laminate layer $3.5 \mathrm{~mm}$ after explosion detonated at the bottom of the vessel.

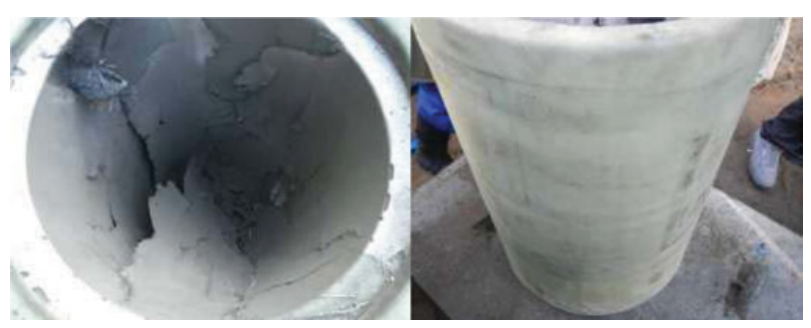

Figure 10. Litter bin after explosion.

displacement of the bin was observed, the check panels were clean without any damage caused by penetration of the fragments.

\section{Conclusions and summary}

Based on the results of this experimental investigation, the following conclusions are drawn:

To ensure the same volume fraction of the fibres in the matrix, very different mass fraction of fibres was required. Despite the volume fraction of fibres was constant for all mixtures, the consistency varied considerably. Some of the fibres at a dosage of 3 vol.\% of fresh mixture were almost unworkable (basalt), other fibres provided good workability even when added in higher amounts (steel). It was observed that the type of incorporated fibres affects flexural strength significantly.

With the addition of any fibres and fibre blends used, the flexural strength was enhanced. Very different contribution to the strength enhancement was observed for each fibre type. The improved mechanical performance (particularly flexural strength) together with improved fracture performance caused by the reinforcement brought about enhanced explosion resistance as well. The level of the enhancement depends on the incorporated fibre type. Extensive further research will be focused on investigation of the relations between the fibre properties (length, tensile strength, modulus of elasticity) and blast resistance of concrete reinforced with them.

Good agreement was concluded between the results of the blast experiments and simulations. Adjusted RHT model can be successfully used for simulations of 
the fibre-concrete material. Numerical simulation can be successfully applied when reduction of the costs connected with development of blast resistance materials and products is required.

The authors wish to express their gratitude and sincere appreciation to the authority of The Technology Agency of the Czech Republic, project No. TA02000162 for financial support.

\section{References}

[1] E.K. Schrader, Impact resistance and test procedure for concrete, ACI J 78 (1981)

[2] Z.S. Tabatabaei, J.S. Volz, J. Baird, B.P. Gliha, D.I.Keener, Int J Impact Eng 57 (2013)

[3] H. Su, J. Xu, Constr Build Mat 45 (2013)
[4] E. Musselman, Blast and impact resistance of carbon fibre reinforced concrete. Ph.D dissertation. (advisor Andres Schokker), The Pennsylvania State University. University park, Pennsylvania, USA, 2007

[5] M. Maalej, S.T. Qeck, J. Zhang, J Mat Civil Eng 17 (2005)

[6] J. Křesťan, J. Krátký, A. Dvořák, Zkušební metoda MT0-B-VTUO 10/9 Hodnocení protivýbuchové odolnosti a míry absorpce rázové vlny ve vzorku na zkušebním stavu T0-B 10/09 (2009)

[7] H. Szklorzova, R. Holešinský, J. Krátký, J. Křesťan, S. Rolc, L. Smetanová. In Proceedings Recent advances in cement and concrete (2012)

[8] Belko, J., Čalkovský, P., Křesťan, J. Testování bezpečnostních objektů M-VTÚO 11/11, Metodika VTÚO Brno (2011) 